\title{
Imagens da crise: tendências ficcionais de Rui Zink
}

\author{
Images of the crisis: Rui Zink's fictional patterns \\ Caroline Valada Becker \\ Pontifícia Universidade Católica do Rio Grande do Sul - Porto Alegre - Rio Grande do Sul - Brasil
}

$\diamond$

Resumo: O escritor Rui Zink, em uma "Nota do autor" inserida ao final do romance $O$ Destino Turístico, explica que pretende criar uma "tetralogia sobre a crise", composta por três romances e um livro de contos - O Destino Turístico (2008), A Instalação do Medo (2012), A Metamorfose e Outras Formosas Morfoses (2014) e Osso (2015). Efetivamente, a crise é o cerne dessas narrativas e une-se à temática da violência, do terrorismo e do medo, dando eco a problemas da Europa contemporânea. A ficção, portanto, mimetiza facetas do mundo empírico, e Rui Zink, por meio de enredos alegóricos e irônicos, desenha a condição humana contemporânea desesperada, assustada e cruel. Aceitando a proposta do autor como chave de leitura (e não como aspecto limitador da análise), este artigo dedica-se ao estudo de tais obras (especificamente os romances) para mapear o signo da crise, utilizando algumas proposições de Zygmunt Bauman $(2008,2014)$.

Palavras-chave: Romance português; Crise; Contemporaneidade.

\begin{abstract}
The writer Rui Zink, in an inserted "Author's Note" at the end of the novel O Destino Turístico (The Tourist Destination), explains that he aims to create a "tetralogy about the crisis", composed of three novels and a book of short stories - O Destino Turístico (2008), A Instalação do Medo (2012, The Installation of Fear), A Metamorfose e Outras Formosas Morfoses (2014, The Metamorphosis and Other Beautiful Morphosis), and Osso (2015, Bone). In fact, the crisis is at the core of theses narratives and joins the violence, the terrorism, and the fear, reflecting contemporary European problems. The fiction, thus, mimics facets of the empirical world; and Rui Zink, by means of allegoric and ironic plots, draws the contemporary human condition desperate, frightened, and cruel. This article accepts the author's proposal as a reading key (and not as an aspect limiting the analysis) and is dedicated to the study of such literary works (specifically the novels) in order to map the sign of the crisis, taking into consideration some propositions of Zygmunt Bauman (2008, 2014).
\end{abstract}

Keywords: Portuguese novel; Crisis; Contemporaneity.

Sim, o futuro não desabrochara um lugar idílico onde o jardim do Éden fosse restabelecido

com todas as castas de animais humanos [...] a viverem em harmoniosa harmonia e paz na terra aos zumães de boa vontade. (ZINK, 2015, p. 210)

- E nenhuma instalação do medo está completa... - Sem o medo da instabilidade dos mercados.

(ZINK, 2012, p. 57)

Mais vale ser tomado por terrorista do que por imigrante.

(ZINK, 2015, p. 21) 


\section{Introdução}

Nas últimas páginas do romance $O$ Destino Turístico, há um breve texto intitulado "Nota do autor", no qual Rui Zink explica ao leitor o projeto literário ao qual o romance pertence: "este livro é o primeiro de uma tetralogia sobre a crise" $(2015$, p. 273$)$, a qual é composta por $O$ Destino Turístico (2008), A Instalação do Medo (2012), A Metamorfose e Outras Formosas Morfoses (2014) e Osso (2015). A crise é definida pelo autor como "uma nova indústria" capaz de subjugar os sujeitos, em alguma medida, escravizando-os; e também como sinônimo da "estupidez humana". Nesses três romances (excluirei da análise o livro de contos), crise significa problemas da ordem ética, econômica e política. Crise ética porque em O Destino Turístico conhecemos um modo distinto de fazer turismo, um lugar em que uma espécie de guerra civil, com bombas e violência, é a grande atração; crise econômica porque $A$ Instalação do Medo descreve a instabilidade do mercado europeu; crise política porque em Osso, em um lugar indefinido, um terrorista é detido.

Certamente, as explanações de escritores acerca da sua ficção não devem restringir interpretações; contudo, suas ideias (veiculadas em entrevistas ou paratextos como prefácios, posfácios, notas do autor etc.) são pertinentes e podem ser utilizadas como chaves de leitura, do mesmo modo que o são as proposições de críticos e teóricos. Nesse sentido, o autor empírico - sujeito social, histórico e ideológico (SILVA, 1983, p.221), responsável pelo ato da produção escrita, exerce uma "função autor" (FOUCAULT, 1969), aspecto que, de modo algum, implica esquecermos os apontamentos de Roland Barthes (1968) sobre a morte do autor ${ }^{1}$. Em outras palavras, aquilo que o escritor disser sobre sua obra não é limitador de leituras, mas sim multiplicador de recepções.

Os vários sentidos permitidos pela escritura relacionam-se à materialidade textual e a suas estratégias textuais (ECO, 1933, p.81) e podem (ou não) ser associados às ideias do autor empírico. Neste artigo, aceito a proposta de Rui Zink - sua tetralogia como uma composição ficcional acerca da crise - e mergulho nos romances para buscar, justamente, imagens dessa crise (de uma crise) por meio de uma análise temática.

\footnotetext{
Em resposta às leituras críticas e teóricas que mapeavam as intenções do autor, Roland Barthes, negando a explicação do texto por meio da trajetória biográfica, centra a análise da obra na sua materialidade, na sua linguagem (daí o conceito de escritura). Para Foucault, o autor enquanto dimensão social e histórica permanece e, em alguma medida, influencia a elaboração de sentidos - é nesse jogo que a imagem do autor empírico é evocada por este artigo.
}

\section{O turismo do medo}

O Destino Turístico subverte o imaginário do turismo; ao invés de praias paradisíacas, hoteis de luxo, parques de diversão ou, até mesmo, natureza selvagem, encontramos um ambiente bélico, uma "zona de morte", um "terreno de caça selvagem e brutal" (ZINK, 2015, p. 149) onde há "Edifícios corroídos, esboroados, calcificados [...] As ruas, essas, eram poeira, dejectos e plásticos pelo chão e pelo ar" (ZINK, 2015, p. 18). A personagem principal, Servajit Duvla - que fornece nome e identidade falsos, Greg, nascido na Suécia - desembarca nesse lugar para tirar férias; nós, leitores, aos poucos, por meio de informações dispersas, descobrimos que o lugar é um país transformado em zona de turismo; toda guerra, violência e ameaça de morte iminente são apenas simulações. Ao invés de visitar a Disney, os turistas visitam um simulacro de guerra, compram pacotes de viagens para um ambiente em colapso e em crise, como se comprassem viagens para Londres ou Rio de Janeiro.

A leitura desse romance revela-se como um jogo, assim como a viagem figura uma brincadeira cujos jogadores (os viajantes) mergulham em um tabuleiro cheio de obstáculos - as experiências de quase morte. Para os leitores, esse produto "férias-em-perigo" é desvendado em sua totalidade quando o narrador utiliza como focalizador a personagem Amadu, taxista contratado por Greg que faz as vezes de guia turístico. Amadu é funcionário do complexo turístico localizado em "Nova Bruxelas" (ZINK, p. 221), o lugar para onde Greg viaja. A inserção do adjetivo "nova" indica uma reconfiguração da geopolítica e nos remete a um tempo futuro não informado, um tempo em que a União Europeia ainda existe, mas há governos (ou ao menos práticas políticas) autoritários.

O capítulo "Nota da comissão" (ZINK, 2015, p. 253) explica o que aconteceu: devido a crises incessantes em diversos países da União Europeia, os governantes executaram estudos para indicar o que cada região (as chamadas "zonas") deveria oferecer ao mundo e, assim, salvar a economia; depois do estudo (uma busca incessante por justificativas científicas e racionais), criaram uma espécie de lei, a "circular 258/14" (ZINK, 2015, p. 256), responsável por implementar o novo status quo.

A região cenário do romance, "Nova Bruxelas", por estar marcada pela "fealdade, miséria, sofrimento, insegurança, más condições de vida, habitação precária, gestão caótica dos centros urbanos, instabilidade em geral e insalubridade pública" (ZINZK, 2015, p. 256), tornouse um espaço de turismo; contudo, um turismo invertido que, além de tornar o sofrimento do outro (o nativo) um espetáculo, proporciona circunstâncias provocadoras de medo. No capítulo "Nota da comissão", há o que seria a 
reprodução de um documento oficial no qual a mudança de paradigma é explicada:

Reconheçamos a dura verdade: o turismo é, nos dias de hoje, a única indústria que resta a regiões que, apesar de todos os fundos estruturais recebidos, provocaram ser incapazes de prosperar de outra forma. Não é contudo qualquer o tipo de turismo defendido. No mundo moderno, dados os desafios que tanto a Europa como o mundo enfrentam, há que reconverter e reformular o conceito mesmo de turismo (ZINK, 2015, p. 255 - grifo meu).

Esse turismo reformulado prevê situações tensas, marcadas por disputas de gangues, terrorismo, execuções e sequestros. O turista compra um pacote de viagem e conhece um país inteiro transformado em parque de diversão cuja atração principal é o medo ${ }^{2}$. O slogan do lugar (afinal, trata-se de um produto) explicita as características do ambiente: "Realize as suas férias de sonho num lugar de pesadelo" (ZINK, 2015, p. 126). Segundo o narrador heterodiegético, "Hoje em dia só insensatos, suicidas, soldados de fortuna, traficantes de armas ou jornalistas com mais sede de glória do que células cinzentas aterravam ali” (ZINK, 2015, p.9).

Greg, a personagem principal, viverá muitas situações-limite. Por exemplo, mergulhará em uma piscina e perceberá que, ao lado, separadas por um vidro, nadam piranhas; terá seu quarto de hotel bombardeado; conhecerá milícias formadas por crianças - "Uma milícia de sete crianças rodeou-os sem hostilidade mas também sem excessivo entusiasmo. O mais velho, decerto o chefe, de resto o único sem metralhadora a tiracolo no peito nu, não teria mais de quinze anos" (ZINK, 2015, p.98-9); presenciará ações de terroristas, como o rapto dos turistas filipinos; verá crianças dilaceradas por bombas - "Uma mulher passara por ele havia nem minutos, descalça, a pé, o filho ao colo de cabeça e braços caídos, deixando um trilho de sangue pelo chão" (ZINK, 2015, p. 25); e descobrirá as regras sociais do país, como as execuções públicas, no mercado, devido a condutas inadequadas:

- Gostou do mercado?

- Sim... Não desgostei.

- E o enforcamento? Uma categoria, não é?

- Sssiim...

- E é muito curioso como os corpos levam mais tempo a soltar o último estertor do que uma pessoa julga. (ZINK, 2015, p. 63)

\footnotetext{
No segundo semestre de 2015, o artista Banksy uniu-se a outros artistas plásticos e criou a "Dismaland", uma Disney às avessas. Os intertextos entre os parques da Disney, "Dimaland" e o romance de Zink são inúmeros e merecem um estudo detalhado, tendo em vista, especialmente, a inversão do mundo utópico (Disney) e mundos distópicos.
}

A naturalidade das personagens (tanto de Greg quanto de outros turistas) diante de situações tão violentas é desconcertante. Os turistas figuram, pois, como consumidores; o produto, por sua vez, são o medo - "O medo, tal como a água, foi transformado em mercadoria de consumo e submetido à lógica e às regras do mercado" (BAUMAN, 2014, p. 125) - e o espetáculo da dor - tanto a dor pessoal quanto a dor do outro, e isso não implica empatia ou misericórdia.

O romance de Zink tematiza a "insensibilidade moral", esse "tipo de comportamento empedernido, desumano e implacável, ou apenas uma postura imperturbável e indiferente, assumida e manifestada em relação aos problemas e atribulações de outras pessoas" (BAUMAN, 2014, p. 20). Tal insensibilidade, como explica Zygmunt Bauman, é traduzida para os sentidos humanos; seja ótico, olfativo ou tátil, trata-se de uma indiferença "resultando na incapacidade de perceber estímulos que em condições 'normais' evocariam imagens, sons ou outras impressões" (BAUMAN, 2014, p. 20), ou seja, causariam reações e, possivelmente, traumas. Em outras palavras, a resposta e a conduta de tais turistas, diante do cenário encontrado, deveria ser outra; entretanto, a liquidez das relações e a consequente "cegueira moral" (para evocar o título do livro de Bauman) engendram um mundo no qual diversão e sadismo andam lado a lado. Quanto ao tempo da diegese, temos a sugestão de uma localização no futuro, tendo em vista a referência à nova ordem mundial devido à ascensão e à decadência de países e regiões - por exemplo, "Agora Goa, o Estado mais bem sucedido do subcontinente indiano, denominado de 'a Califórnia do Oriente"” (ZINK, 2015, p. 230).

Os turistas são clientes; segundo a personagem Amadu, eles não reparavam como tudo era armado (como a violência era uma simulação) "Porque eram consumidores. Porque eram - palavra mágica clientes" (ZINK, 2015, p. 112). E consumidores são a representativa população da modernidade líquida, essa "comunidade global de consumidores. [...] consumidores obrigados a se comportar a fim de se qualificar para o clube" (BAUMAN, 2014, p. 68). No caso do romance, um clube de desajustados, sujeitos solitários e traumatizados à procura de experiências que possam dar sentido às suas vidas. A personagem principal do romance, Greg/Servajit, busca incessantemente a morte; Amadu observa-o e descreve-o como um suicida, um sujeito diferente dos demais turistas que por ali passeiam, e que ali não deveria estar, uma vez que, antes de embarcarem para esse lugar turístico, a agência fazia uma triagem para descartar pessoas realmente suicidas:

Este Guereg, por acaso, era diferente. Não uma surpresa completa, claro, Amadu nascera ali, era um 
veterano, mas um turista felizmente de tipo mais raro: daqueles que iam à zona não para ver atrocidades, antes para se perderem nelas. [...] Amadu suspeitava que ele [Greg] fosse mesmo suicida. Não um tonto em busca de emoções fortes visitando uma zona de guerra, mas alguém que, por um motivo qualquer, se queria entregar, abandonar, auto-aniquilar (ZINK, 2015, p. 218-9 - grifo meu).

O "motivo qualquer" referido por Amadu significa, para Greg, culpa e trauma, os quais são narrados em dois capítulos - "Um acontecimento sem importância" (ZINK, 2015, p. 129) e "Tudo estaria bem se" (ZINK, 2015:179) que se descolam da temporalidade dos fatos narrados durante a viagem de Greg e relatam o passado da personagem. Quando jovem, Greg assistiu a uma cena preocupante, dois rapazes humilhando uma moça; ele não a ajudou e, dias depois, soube que fora estuprada e assassinada; muitos anos depois, o filho de Greg, um jovem adulto, brigou no trânsito, agrediu o motorista, tentou fugir da cena e atropelou pessoas. Greg percebe um espelhamento entre pai e filho, como um tempo em espiral que se repete e reitera a cegueira moral e a "insensibilidade moral" inerentes ao viver:

Por isso não podia perdoar ao filho. Era assim tão difícil de compreender? Não por o filho ter feito diferente dele, mas por o filho não ter feito diferente dele. Isto para já não dizer que fora ele quem lhe oferecera o carro. Ao abrir a ferida, mostrando o pus sob a cicatriz que parecia sarada, o filho desonrara-o (ZINK, 2015, p. 237 - grifo meu).

A atitude de indiferença exercitada por sujeitos pertencentes a gerações distintas suscita, em Greg, traumas e, principalmente, desejo de morrer; por isso ele procura esse destino turístico cujas características sintetizam e exemplificam a cegueira do viver, desenhando um mundo em crise - por um lado, crise da alteridade e da empatia; por outro lado, crise econômica e social, uma vez que, no mundo ficcional de $O$ Destino Turístico, países e regiões esfacelaram-se e tornaram-se centros de entretenimento cuja atração principal é o espetáculo da dor. Como explicam os governantes na já referida "Nota da Comissão",

[...] Por causa de uns escassos nove ou dez milhões nesta ou naquela região, fará sentido pôr em risco a saúde financeira da comunidade europeia inteira? [...] É neste sentido que a comissão propõe a reconversão das regiões mais afectadas em zonas. Por zona entenda-se um sistema em monocultura dedicado a uma única actividade que lhe permita, por um lado, deixar de depender de recursos que a comissão não pode continuar a canalizar para lá e, por outro, uma forma de servir o colectivo de forma mais organizada e útil do que até agora (ZINK, 2015, p.255).
Tais governantes, ainda nessa carta, explicam que os objetivos principais da reorganização são o bemestar, a democracia e o equilíbrio, tendo em vista que "A comunidade é o bem, o bem é a comunidade" (ZINK, 2015 , p. 257). O cenário apresentado nesse mundo futuro, ainda organizado em União Europeia, é sombrio; a "comunidade" restringe-se ao bem-estar de poucas pessoas - aquelas que trabalham no parque turístico, por exemplo, não merecem cuidados e, quando chegam a determinada idade, são executadas. Democracia e equilíbrio são princípios disponibilizados, também, apenas para alguns; outros, como aqueles que vivem na zona da "Nova Bruxelas", estão em meio à violência e ao caos. Eis a crise.

\section{A imposição do medo}

No romance A Instalação do Medo, dois homens batem à porta de uma mulher e anunciam "Viemos para instalar o medo" (ZINK, 2012, p. 11). Seguem as diretrizes do governo, cumprem a lei "Directiva no 359/13. Portaria 8 " que exige: "Todos os lares devem ter o medo instalado num prazo de 120 dias" (ZINK, 2012, p. 13). Trata-se de uma medida para conquistar o progresso, "é pelo bem do país" (ZINK, 2012, p.11), explicam os instaladores, representantes do estado "apenas a cumprir ordens" (ZINK, 2012, p. 14). De modo autoritário, por meio de uma lei que permite a "invasão" das casas, o governo coordena as pessoas. Aquele que abre a porta não tem escolha, é preciso dizer sim, participar da engrenagem imposta.

O processo de instalação tem dois momentos: a instalação em si e a demonstração - são quatro capítulos, I. Os visitantes, II. Instalação; III. Demonstração; IV. Corolário. A primeira etapa acontece na sala (antes, era preciso ir aos quartos, mas a narrativa não diz por que, sugerindo que, mesmo antes da lei, o medo era instalado); a duração do processo é variável - "Antigamente levava anos. Agora, com as novas tecnologias, é apenas questão de minutos" (ZINK, 2012, p.17). Não sabemos quais ações estão envolvidas na instalação; sabemos, apenas, que algo é colocado na parte interna das paredes: "A mulher não tenta perceber os pormenores da instalação. Cabos, ligações, parafusos, o barulho do berbequim. Ao fim de um quarto de hora já parte da parede está rebocada e o chão sujo de poeira e detritos, mas a mulher não ousa protestar" (ZINK, 2010, p. 27).

Uma vez instalada a aparelhagem, principia a "demonstração". A partir desse momento, os dois homens contam histórias; apresentam vídeos, imagens e hologramas (possivelmente, os aparelhos instalados sejam projetores, computadores, televisão etc.). A cada história narrada, um medo nasce; na diegese, portanto, essas histórias são narradas pelos instaladores, os quais 
utilizam recursos tecnológicos para isso. No objeto livro, tais histórias vêm em itálico, demonstrando tratar-se de uma pausa no enredo para contemplarmos as tais narrativas pedagógicas (Cf. ZINK, 2012, p.35, 45, $63,93,113,129,157,160)$.

O medo é utilizado para ensinar; as histórias narradas são, pois, um recurso pedagógico - "O medo não é só necessário, é também apelativo. E educativo. É a forma mais bela de explicar o mundo e de ordenar o mundo" (ZINK, 2012, p.34). Uma população com medo é uma comunidade facilmente controlada. Este é o objetivo dos instaladores, em nome do governo oficial: controlar. Os instaladores explicam que o medo é "um processo de cooperação" (ZINK, 2012, p. 77) cujos sentidos se multiplicam:

- O medo é pedagógico.

- É muito interessante.

- Ajuda a compreender a natureza humana.

- Ajuda a domesticar os maus instintos.

- O medo tem o seu quê de experiência científica.

- Ajuda a compreender melhor o modelo social.

- É muito interessante.

- E comovente (ZINK, 2010, p. 109).

Bauman define o medo como o nome que damos à incerteza, "nossa ignorância da ameaça e do que deve ser feito - do que pode e do que não pode - para fazê-la parar ou enfrentá-la, se cessá-la estiver além do nosso alcance" (2008, p. 8). O medo do desconhecido é, justamente, o primeiro medo apresentado pelos instaladores: "A senhora está a sentir-se hesitante, não é? É bom sinal, é sinal de que a instalação do medo já começou" (ZINK, 2010, p. 19). Depois, eles descrevem o medo da natureza, narrando a história de uma criança perdida na floresta, evocando, evidentemente, os contos de fadas e reiterado a faceta pedagógica das narrativas: "Um dia, sem avisar, a mãe manda o filho à floresta e ser devorado pelos lobos. A criança não compreende o porquê de tamanha crueldade, mas o que pode fazer?" (ZINK, 2012, p. 35).

Em seguida, será a vez do medo da violência urbana. Duas histórias envolvem esse mote; a primeira delas narra uma situação de estupro e assalto:

Você mora nesse bairro e tem medo. Tem medo, e quem não teria? É uma selva de asfalto, um deserto, as ruas estão desertas. Mas é um falso deserto. As ruas apenas parecem desertas. Ainda ontem uma senhora já de idade foi violada na escada do seu prédio. Cometeu um erro fatal, ficou a procurar as chaves [...] nem sequer a roubaram, foi só mesmo para se divertirem, por maldade, enfim [...] (ZINK, 2010, p. 46-7).

A segunda narrativa centrada na violência urbana descreve o rapto de crianças e vem em formato de bilhete, como uma circular distribuída no bairro:
[...] Avisem os vossos filhos que, se encontrarem uma criança com sotaque estrangeiro que chora pela estrada [...], peguem nela e levem-na para o posto da GNR, BT, SEF, Polícia [...]. ISTO É UM NOVO MÉTODO PARA RAPTAR AS CRIANÇAS E JOVENS PELAS MÁFIAS ESTRANGEIRAS A OPERAR NO NOSSO PAÍS (ZINK, 2012, p. 160).

Temos, ainda, o medo de doenças e de qualquer vírus avassalador - "Um vírus atravessa o ar. É invisível, incolor, indolor - até ver" (ZINK, 2012, p. 63); há o medo da marginalização social e consequente violência - "Quando estamos frente a frente reparamos ambos que ele nem sequer segura bem na pistola" (ZINK, 2012, p. 114); e o medo do Alzheimer, doença bastante simbólica, signo do esquecimento do passado e da história - "O medo de não me reconhecer ao espelho. De só lá encontrar, na imagem reflectida, sorrindo gorda e satisfeita, a doença" (ZINK, 2012, p. 158).

Entretanto, o principal medo, segundo os instaladores, é este: o medo do mercado econômico, da instabilidade dos mercados, da crise do mercado econômico; e sem esse medo, "nenhuma instalação está completa" (ZINK, 2010, p. 57). Os mercados estão, pois, em crise:

- 'Os mercados estão desconfiados.'

- 'Os mercados não estão satisfeitos.'

- 'Pedem mais reformas estruturais.'

- 'Precisam de ser apaziguados com sacrifícios.'

- 'Maior celeridade nas reformas.'

- 'Urge agilizar a economia.' (ZINK, 2012, p. 56).

Uma vez enunciado esse assunto, marcas de temporalidade e de espacialidade aparecem, quando os instaladores explicam: "Os europeus estão a assistir um filme de terror. De todos os lados surgem ameaças de desastre." (ZINK, 2010, p. 85). Em seguida, ambos sugerem batizar a crise de "EUROPA2014" (ZINK, 2010, p. 86). A crise econômica será comparada, ainda, a uma pandemia, a um vírus que se alastra (relembrando que este é dos motes das narrativas pós-apocalípticas); os instaladores dirão que essa tragédia dialoga com tantas outras (Cf. ZINK, 2010, p. 84), como Pompeia (79 d.C), Titanic (1912), Sarajeivo (1914), Berlim (1939), e definirão:

- Não há dinheiro. Os cofres estão vazios.

- Temos de vender as reservas de ouro.

- Vender os anéis.

- Vender os dedos, se necessários.

- A verdade é só uma, minha senhora.

- Não há salva-vidas para todos.

- Essa é a realidade.

- Há que fazer sacrifícios humanos para salvar os humanos que for possível salvar (ZINK, 2010, p. 57).

Os "sacrifícios humanos", na crise econômica, implicam, por um lado, desemprego - os jovens têm 
medo de não conseguir emprego; os mais velhos, de o perder; privatização - "Quem quer saúde, pague-a; quem quer educação, pague-a (ZINK, 2010, p. 108); por outro lado, descarte dos mais velhos, descritos como "gorduras excedentes" e "improdutivos" (ZINK, 2012, p. 104). A crise econômica, portanto, é responsável por incitar o medo mais expressivo da contemporaneidade; no romance, essa crise, por meio de comparações, torna-se signo de tragédias e colapsos, incorporando mais um receio ao repertório já instaurado.

Uma vez interiorizados os medos, o sujeito terá uma visão de mundo amparada na insegurança e na vulnerabilidade - mesmo quando não houve uma ameaça genuína - e, assim, a atitude de controle estará integrada à conduta das pessoas (Cf. BAUMAN, 2008, p.9). A crise da economia, no mundo empírico, ganha contornos de catástrofe; a ficção de Zink evoca essa potência avassaladora das redefinições econômicas e o consequente medo implementado: "A economia está a ceder, como um tecto sob o peso cada vez mais crescente das água. A economia está a ceder, podemos começar a ver as brechas, as fissuras, as rachas" (ZINK, 2012, p. 88). Eis a crise.

\section{A presença do medo}

Um atentado terrorista interrompido e um processo de interrogação para desvendar as intenções do terrorista - esse é o simples enredo de Osso, um texto quase teatral, uma vez que apresenta apenas diálogos. Dos livros anteriores analisados, nesta obra, permanecem o tom insólito e, em termos temáticos, a presença de um governo ou ordem oficial, afinal, "as forças da ordem" (ZINK, 2015b, p. 11) estão a resolver o (frustrado) atentado no aeroporto (localizado em um lugar/território/ país não informado, indefinido); depois, no interrogatório, os representantes dessa ordem cumprem protocolos, o que inclui tortura, a qual o interrogado, obviamente, não gostaria de vivenciar:

Não me parece que ser torturado faça o meu género.

Não se preocupe. Não vamos chamar tortura.

Menos mal, mas ainda assim...

Tem algo contra?

Por acaso tenho. Então se eu já confessei...

Não importa. Protocolo.

Protoquê?

Protocolo.

Mas a tortura não é ilegal no vosso país?

Tem inteira razão.

Então como me podem torturar?

Por isso mesmo é que não lhe chamamos tortura (ZINK, 2015b, p. 16).

O terrorista defende-se e explica que sua ação não era maldosa:
A verdade é que eu tinha um primo que eu pensava que andava metido no negócio do azeite mas afinal era o do terrorismo e quando eu lhe contei que gostava de viajar mas havia o problema do dinheiro ele disse que podia falar com os sócios a ver se arranjava qualquer coisa (ZINK, 2015b, p. 22).

A ironia e o humor, portanto, emergem do discurso da personagem-terrorista; segundo ele, "Tempos desgraçados pedem desesperos engraçados" (ZINK, 2015b, p. 93). Em outras palavras, a desgraça do terrorismo pede uma postura desesperada, capaz de incitar sorrisos e risadas - justamente o tom do livro Osso, cujo último capítulo, "Moral da história", sintetiza:

Um terrorista entra num bar com uma bomba na mão. O dono do bar avisa que tem de deixar a bomba lá fora. O terrorista diz-lhe: estava a brincar, eu não sou terrorista, olhe só, isto não é uma bomba, é um isqueiro. $\mathrm{E}$ para mostrar que é verdade, acende o isqueiro. O dono do bar replica, com ar triste: eu também estava a brincar, isto não é um bar, é um posto de gasolina (ZINK, 2015b, p. 133).

Nesse romance, a crise está implementada e travestese ora de terrorismo, ora de incomunicabilidade. $\mathrm{O}$ trecho acima dialoga com as marcas de gênero da fábula, breve texto narrativo que ensina algo. E retornamos, assim, à (possível) tendência pedagógica da "contação de histórias", já desenvolvida n'A Instalação do Medo. Na moral da história de Osso, tanto "Terrorista" quanto "dono de bar" mentem, omitem ou manipulam informações; consequentemente, não há comunicação ou compreensão; há desencontro e caos, bem como a indicação de uma catástrofe, uma explosão anunciada - uma verdadeira metáfora da contemporaneidade, um mundo prestes a explodir.

O diálogo entre o terrorista e o sujeito que conduz o interrogatório segue a mesma tendência do excerto acima, uma conversa desencontrada, dissimulada e inócua, como esta sequência evidencia:

\section{Então?}

Então o que? Então nada.

Mas vocês veio fazer terrorismo.

Ó homem, vim fazer terrorismo coisa nenhuma. Vim fazer turismo. Turismo.

Então e a bomba?

A bomba, a bomba. Lá está você com a bomba. Não tem outro assunto de conversa? A bomba, a bomba...

A bomba.

Ora. Uma infantilidade. Não sei o que me deu. Uma folia de juventude (ZINK, 2015b, p. 88-9).

O terrorista tecerá uma reflexão e afirmará que o século XXI é o século do terrorismo, considerando-o a terceira maior indústria do mundo, "o motor da economia, o guardião da democracia” (ZINK, 2015b, p. 128). O 
terrorismo suscita medo, uma sensação não abstrata ou genérica, mas traduzida para algo concreto - homensbomba, explosões e sequestros de avião - e disperso na vida cotidiana moderna: "O medo de sofrer um atentado terrorista é, sim, concreto e específico, uma vez que trabalha com a ideia de insegurança individual/social/ governamental originária de uma ameaça constante, real e iminente, evocada por um fenômeno específico" (CARDOSO, 2014, p. 130-1).

O terrorismo faz-se presente nos três romances analisados. Em $O$ Destino Turístico, os terroristas estão pelas ruas; em A Instalação do Medo, os instaladores explicam que o terrorismo "está a dar" (ZINK, 2012, p. 141) e, evidentemente, é assustador, embora seja "muito menos sofisticado que o pavor económico. E não tão eficaz" (ZINK, 2012, p. 141). Compreender o terrorismo - como explicitam os diálogos de Osso - é impossível, pois, segundo um dos instaladores do medo, "Tentamos compreender. Mas não há nada para compreender" (ZINK, 2012, p. 142), "haja vista a sua característica milenar de almejar uma mudança por meio da utilização de violência física e psíquica, principalmente frente à sociedade civil" (CARDOSO, 2014, p. 128).

\section{Conclusão}

Os subtítulos utilizados ao longo deste artigo - o turismo do medo, a imposição do medo, a presença do medo -, em alguma medida, sintetizam os três romances analisados: turistas à procura do medo; um governo que impõe medo; o medo instaurado pelo terrorismo. $\mathrm{O}$ sentimento de medo é desdobramento e consequência da crise - crise da alteridade, do bem-estar social e da insegurança; e todos os medos representados nas obras de Zink são resultado de males morais, ações intencionais e premeditadas (Cf. BAUMAN, 2008, p. 79), seja da ordem institucional (como governo e entidades), seja da ordem individual (como ações terroristas). O medo emerge no dia a dia, apresenta distintas facetas e funções e alimenta nossa "imaginação perturbada e apocalíptica" (Cf. BAUMAN, 2014, p. 116), uma resposta às múltiplas crises enfrentadas pelos sujeitos. O medo, explica Bauman, está conosco o tempo todo, "alimentando nossa mídia sensacionalista e privando-nos do doce sonho de que haja em algum lugar (ou pelo menos deveria haver) uma ilha distante onde pudéssemos nos sentir absolutamente seguros e felizes" (BAUMAN, 2014, p. 117).

Para Bauman (Cf. 2008, p. 10), existem três perfis de perigo que causam medo. O primeiro ameaça corpo e propriedades - seriam os medos explorados em $O$ Destino Turístico, pois as personagens deparam-se com a possibilidade da morte, e em Osso, pois ataques terroristas matam e destroem propriedades. $\mathrm{O}$ segundo medo, mais geral, ameaça a "durabilidade da ordem social e a confiabilidade nela, da qual depende a segurança do sustento (rende, emprego) ou mesmo da sobrevivência no caso de invalidez ou velhice" (BAUMAN, 2008, p. 10). Essa descrição aplica-se ao romance $A$ Instalação do Medo, porque nele há o medo do descontrole econômico, da decadência dos mercados e da presença do desemprego. Por fim, há os perigos (e consequentemente os medos) que "ameaçam o lugar da pessoa no mundo - a posição na hierarquia social, a identidade (de classe, de gênero, étnica, religiosa) e [...] a imunidade à degradação e exclusão sociais" (BAUMAN, 2008, p. 10), tematizados, também em $A$ Instalação do Medo, já que existe um governo opressor que invade as casas; em Osso, pois o terrorismo carrega implicações religiosas e étnicas.

O medo e a crise ou a crise e o medo têm desenhado distopias - por isso, a tetralogia de Rui Zink flerta com esse gênero literário, inscrevendo em seus enredos imagens do imaginário distópico (resultado das crises do século XX). Da imagem de um futuro que oferece o medo como mercadoria à ação do governo que bate à porta e instala o medo, o imaginário da crise criado por Zink alerta os leitores acerca do nosso tempo presente e futuro - tempos de crise em uma Europa cercada por desafios - a insensibilidade humana, a economia, os terroristas (e que coincidência chamar-se "Nova Bruxelas" o país turístico do medo e do terrorismo, tendo em vista que, em março de 2016, o Estado Islâmico protagonizou atentados em Bruxelas). A crise existe; a arte torna-a ficção.

\section{Referências}

BARTHES, Roland. A morte do autor. In: O rumor da língua. São Paulo: Brasiliense, 1988.

BAUMAN, Zygmunt. Medo Líquido. Tradução de Carlos Alberto Medeiros. Rio de Janeiro: Jorge Zahar Ed., 2008.

BAUMAN, Zygmunt; DONSKIS, Leonidas. Cegueira moral: a perda da sensibilidade na modernidade líquida. Tradução de Carlos Alberto Medeiros. Rio de Janeiro: Jorge Zahar Ed., 2014.

CARDOSO, Tatiana de Almeida Freitas R. A mundialização do terrorismo: a (re)definição do fenômeno após o 11 de Setembro. In: Direitos Humanos e Terrorismo. BORGES, Rosa Maria Zaia; AMARAL, Augusto Jobim do; PEREIRA, Gustavo Oliveira de Lima (Org.). Porto Alegre: EDIPUCRS, 2014.

SILVA, Vitor Manuel de Aguiar e. A comunicação literária. In: Teoria da literatura. 5. ed. Coimbra: Almadina, 1983. Vol. 1.

FOUCAULT, Michel. O que é um autor. Lisboa: Vega, 2006. ZINK, Rui. O Destino Turístico. Portugal: Teodolito, 2015. ZINK, Rui. A Instalação do Medo. Portugal: Teodolito, 2012. ZINK, Rui. Osso. Portugal: Teodolito, 2015b.

Recebido: 13 de abril de 2016. Aprovado: 25 de junho de 2016. Contato: carol.valada@hotmail.com 